\title{
A STUDY ON PREVALENCE OF PULMONARY CANDIDIASIS AMONG TUBERCULOSIS PATIENTS AND USE OF CHROMAGAR IN IDENTIFICATION OF CANDIDA SPECIES
}

\author{
${ }^{1}$ Dr. S. Mathavi*, ${ }^{2}$ Dr. R. Shankar, ${ }^{3}$ Dr. A. Kavitha, ${ }^{4}$ Dr. G. Sasikala, ${ }^{5}$ Dr. Indra Priyadharsini \\ ${ }^{1}$ Associate Professor, Department of Microbiology, Vinayaka Mission's Kirupananda Variyar Medical College, Salem \\ ${ }^{2}$ Associate Professor, Department of Community Medicine, Vinayaka Mission's Kirupananda Variyar Medical College, \\ Salem \\ ${ }^{3}$ Associate Professor, Department of Microbiology, Vinayaka Mission's Kirupananda Variyar Medical College, Salem \\ ${ }^{4}$ Assistant Professor, Department of Microbiology, Vinayaka Mission’s Kirupananda Variyar Medical College, Salem \\ ${ }^{5}$ Professor and head, Department of Microbiology, Vinayaka Mission's Kirupananda Variyar Medical College, Salem
}

* Principal and Corresponding author's E-mail- $\underline{\text { drmathavimicro@gmail.com }}$

\begin{abstract}
Introduction: In recent years, fungal infections are on the rise due to various predisposing factors such as long term administration of antibiotics, use of steroids, pulmonary tuberculosis, immunosuppressive drugs and HIV infection. When host resistance is lowered, these opportunistic fungi may become fatal. Candida albicans was the most important pathogen causing pulmonary candidiasis. In recent times, there is increase in incidence of non-albicans Candida. Identification to the species level becomes mandatory in the selection of appropriate antifungal agents. Aim: To find out the prevalence of Candida co-infection among pulmonary tuberculosis patients and to identify the species of Candida using CHROMagar. Materials \& Methods: A total of 107 smear positive pulmonary tuberculosis patients were included in this study. Two consecutive sputum samples were collected and subjected to gram staining. Only those samples which showed pus cells with budding yeast cells and pseudohyphae in direct gram stain were cultured on Sabouraud's dextrose agar (SDA) with gentamycin. The Candida grown was identified and speciated based on the color produced on CHROMagar Candida. Results: Out of 21 Candida isolates, 14 were C. albicans (66.7\%), 2 were C. tropicalis (9.5\%), 2 were C.krusei (9.5\%), 2 were C. parapsilosis $(9.5 \%)$ and one was C. glabrata (4.8\%). Conclusion: The secondary fungal infections are associated with persistence of lung symptoms inspite of successful completion of antituberculous therapy. Hence adequate measures need to be taken for the early identification and treatment of these opportunistic infections.

Keywords: Pulmonary tuberculosis, Candida albicans, non-albicans Candida, antifungal agents
\end{abstract}

\section{INTRODUCTION:}

In recent years, fungal infections are on the rise due to various predisposing factors such as long term administration of antibiotics, use of steroids, pulmonary tuberculosis, immunosuppressive drugs and HIV infection ${ }^{1}$. Candida species are one of the potentially pathogenic fungal agents in patients with bronchopulmonary disease. They are associated with secondary infections in tuberculosis patients ${ }^{2}$. When host resistance is lowered, these unrecognized opportunistic fungi may affect the progress of disease or may even become fatal ${ }^{1}$, 3. Hence, there is need to consider the possible importance of these saprophytic organisms when they are found repeatedly and evidently from the site of the lesion ${ }^{4}$. Candida albicans (C. albicans) was considered the most important pathogen causing secondary infection in pulmonary tuberculosis ${ }^{5}$. C. albicans stimulated growth of M. tuberculosis of reduced viability ${ }^{6}$. Another study confirmed the effect of polysaccharide fraction of C.albicans for enhancement of the growth as well as reduction of the generation time of tubercle bacilli ${ }^{6}$. But in recent times, there is increase in incidence of nonalbicans Candida infection ${ }^{6}$. Most of the non-albicans Candida usually exhibit a reduced susceptibility to the common antifungal agents ${ }^{5}$. Hence identification of Candida to the species level has become mandatory to aid the selection of appropriate antifungal agents in treatment of invasive candidiasis. Identification of Candida species by conventional methods is a cumbersome and time consuming process. Usage of chromogenic medium could be a substitute to conventional identification techniques for rapid identification of Candida spp. 
Aim:

The present study was undertaken to find out the prevalence of Candida co-infection among pulmonary tuberculosis patients in Salem district and to identify the species of Candida using CHROMagar.

\section{MATERIALS \& METHODS:}

A total of 107 smear positive pulmonary tuberculosis patients were included in this study done during JuneSeptember 2013 in Vinayaka Mission's Kirupananda Variyar Medical College, Salem. The study was done after obtaining informed consent from the patients and instituitional ethical committee clearance. Two consecutive sputum samples were collected from each patient and subjected to gram staining and culture. A detailed history regarding smoking, alcohol consumption, calorie intake etc., was collected from the patients by administering a questionairre. The criteria for diagnosis of candidiasis were based on the presence of pus cells with budding yeast cells and pseudohyphae in direct gram stain ${ }^{1}$. Only those samples which satisfied this criterion were subjected to culture on Sabouraud's dextrose agar (SDA) with gentamycin. The samples which showed only budding yeast cells without pseudohyphae were excluded from the study. The Candida grown on SDA was speciated by inoculating onto CHROMagar Candida. After inoculation onto CHROMagar, the plates were incubated for 48 hours at $37^{\circ} \mathrm{C}$ and the colonies were identified based on the color produced by the Candida species. Light green coloniesCandida albicans, blue colonies with pink halo Candida tropicalis, purple colonies- Candida glabrata, pink colonies- Candida krusei, cream colonies- Candida parapsilosis.

\section{RESULTS:}

Out of 107 sputum positive pulmonary tuberculosis patients, Candida coinfection was observed in 19 patients (17.7\%). Among these 19 samples, two samples showed dual infection (with two different species of Candida in same sample). Hence total number of Candida isolated was 21.

Candida albicans was the predominant species causing secondary infection. Out of 21 Candida isolates, 14 were identified as $C$. albicans (66.7\%), 2 were $C$. tropicalis (9.5\%), 2 were C. krusei (9.5\%) and C. parapsilosis was also isolated from 2 cases $(9.5 \%)$. C. glabrata was isolated from one sample (4.8\%).

Table 1: Species distribution of Candida $(n=21)$

\begin{tabular}{|c|l|c|}
\hline S.No & Fungal species & No of isolates \\
\hline 1 & Candida albicans & $14(66.7 \%)$ \\
\hline 2 & Candida tropicalis & $2(9.5 \%)$ \\
\hline 3 & Candida krusei & $2(9.5 \%)$ \\
\hline 4 & Candida parapsilosis & $2(9.5 \%)$ \\
\hline 5 & Candida glabrata & $1(4.8 \%)$ \\
\hline
\end{tabular}

C.albicans was the predominant species causing coinfection among pulmonary tuberculosis patients in our study.

Table 2: Distribution of Candida infection based on DOTS category

\begin{tabular}{|c|l|c|c|c|c|}
\hline \multirow{2}{*}{ S.No } & \multirow{2}{*}{ Fungal species } & \multicolumn{3}{c|}{ DOTS category } & \multirow{2}{*}{ Total } \\
\cline { 3 - 5 } & & category 1(74) & category 2(32) & XDR TB(1) & \\
\hline 1 & Candida albicans & 8 & 5 & 1 & 14 \\
\hline 2 & Candida tropicalis & 2 & 0 & 0 & 2 \\
\hline 3 & Candida krusei & 1 & 1 & 0 & 2 \\
\hline 4 & Candida parapsilosis & 1 & 1 & 0 & 2 \\
\hline 5 & Candida glabrata & 1 & 0 & 0 & 1 \\
\hline & Total & $13(17.57 \%)$ & $7(21.87 \%)$ & 1 & 21 \\
\hline \multicolumn{4}{|c|}{ P value $=0.687$} \\
\hline
\end{tabular}

Statistically, the isolation of Candida was independent of the Category of the disease as shown in table 2.

Table 3: Distribution of Candida infection in different gender $\&$ among alcoholics

\begin{tabular}{|l|l|l|l|l|}
\hline \multirow{2}{*}{ Fungal infection } & \multicolumn{2}{|c|}{ Gender } & \multicolumn{2}{c|}{ Alcohol } \\
\cline { 2 - 5 } & Males & Females & Alcoholics & Non- alcoholics \\
\hline Candida species(n=21) & $12(57.14 \%)$ & $9(42.86 \%)$ & $11(52.38 \%)$ & $10(47.62 \%)$ \\
\hline
\end{tabular}

There is no gender specific prevalence of fungal infections among TB patients. The secondary Candida infection is also not related to alcohol consumption in our study as shown in table 3 . 
Table 4: Distribution of Candida infection among smokers

\begin{tabular}{|c|l|c|}
\hline $\begin{array}{c}\text { S. } \\
\text { No. }\end{array}$ & \multicolumn{1}{|c|}{ Smoking } & No of Candida isolated $(\mathbf{n = 2 1})$ \\
\hline 1 & Smokers & $15(71.43 \%)$ \\
\hline 2 & Non-smokers & $6(28.57 \%)$ \\
\hline \multicolumn{2}{|c|}{$P$ value $<.005$} \\
\hline
\end{tabular}

In our study, smoking was significantly associated with incidence of Candida infection among tuberculous patients. This was found to be statistically significant.

Table 5: Distribution of Candida infection based on BMI

\begin{tabular}{|c|c|c|}
\hline S. No & $\begin{array}{c}\text { Body Mass } \\
\text { Index }\end{array}$ & $\begin{array}{c}\text { No of Candida isolated } \\
(\mathbf{n = 2 1})\end{array}$ \\
\hline 1 & $<15$ & $4(19.04 \%)$ \\
\hline 2 & $15-18$ & $12(57.14 \%)$ \\
\hline 3 & $18.1-21$ & $3(14.28 \%)$ \\
\hline 4 & $21.1-24$ & $2(9.52 \%)$ \\
\hline \multicolumn{2}{|c|}{$P<.005$} \\
\hline
\end{tabular}

Prevalence of fungal infection is more common in patients having low BMI when compared to those with normal or high BMI and this difference was found to be statistically significant.

\section{DISCUSSION:}

The present study shows $18 \%$ of pulmonary tuberculosis patients to be co-infected with Candida spp. This is in accordance with the study done by Sehar Afshan Naz and Perween Tariq ${ }^{6}$ in which $15.2 \%$ of co-infection with Candida species was documented. But this is low when compared to the study of VP Baradkar et al ${ }^{1}$ which shows a prevalence of $26 \%$ co-infection with Candida species. Candida forms a part of normal microbial flora of healthy individuals. When the host resistance is lowered, these commensals turn into aggressive pathogens causing life threatening systemic infections. The role of Candida species as secondary invaders in patients having pre-existing diseases like pulmonary tuberculosis is well documented ${ }^{6}$.

Among the Candida spp, C. albicans was the commonest organism causing secondary infection in our study. $C$. albicans constituted $66.7 \%$ of the total Candida isolates. This correlates with the study conducted by Kali A et $\mathrm{al}^{2}$ which also demonstrates $C$. albicans to be the commonest species causing secondary infection comprising $50 \%$ of the total Candida isolates.

Although $C$. albicans was the commonest species causing secondary infection, other non-albicans Candida species were also associated with secondary infection in our study. The non-albicans Candida isolated were $C$. tropicalis (9.5\%), C.krusei (9.5\%), C. parapsilosis $(9.5 \%)$ and $C$. glabrata $(4.8 \%)$. This is similar to the study of Latha et $\mathrm{al}^{5}$ which also showed increased incidence of non-albicans Candida infection.

Our study revealed that the CHROM agar was very useful in rapid identification of Candida species. The media was very sensitive in identifying most of the species like $C$ albicans, C.tropicalis, C.glabrata, $C$. parapsilosis and C.krusie. It was also highly useful in identifying dual infections. The colony morphology and the colour of the colony were consistent for over a period of 4-5 days. Hence determination of colour was simple and not cumbersome. This finding correlated with other studies using chromogenic medium ${ }^{5}$. Early identification of Candida species aids in early appropriate treatment thereby reducing the morbidity and mortality in these patients $^{7}$

Coexistence of Candida and tuberculosis is well documented since a long time ${ }^{8}$. These Candida infections, when associated with pre-existing disease, may cause many complications in the primary disease. It has also been observed that secondary fungal infections in the lungs of pulmonary tuberculous patients are associated with marked cough, expectoration, dyspnea and fever ${ }^{6}$.

Weak immune status, destruction of lung tissues and lesions formed due to TB are the predisposing factors for fungal infections ${ }^{9}$. Prolonged treatment with antibiotics and corticosteroids also makes these patients more prone for opportunistic infections ${ }^{10}$. This is very well documented in our study which shows candida infection is more common among smokers and those with low Body Mass Index (BMI).

Though $C$. albicans seems to be the commonest pathogen associated with pulmonary candidiasis, there is also increase in the incidence of non-albicans Candida. Among non-albicans Candida species, C. tropicalis has been emerging as a new opportunistic pathogen to cause severe invasive disease. C. tropicalis has an apparently greater capacity than C.albicans to invade the deep tissues of immunocompromised host ${ }^{6}$.

Hence adequate measures should be taken for the prevention and treatment of these opportunistic infections in tuberculous patients. Options of antifungal drugs available to treat chronic candidiasis infections are limited; moreover resistance to the available drugs may result in failure of treatment ${ }^{9}$. Identification of Candida to the species level has become mandatory for selecting the appropriate antifungal agents in treatment of invasive candidiasis because most of the non albicans Candida exhibit reduced fluconazole susceptibility ${ }^{5}$.

\section{CONCLUSION:}

C. albicans continues to be the commonest pathogen responsible for pulmonary Candidiasis. Smoking and low BMI are the factors determining the prevalence of fungal infection among our study population. The secondary fungal infections in lungs of tuberculous patients are associated with persistence of lung symptoms inspite of successful completion of antituberculous therapy. Hence adequate measures need to be taken for the early identification and treatment of these opportunistic infections. In addition, identification to the species level becomes mandatory in selecting the appropriate antifungal agents. 


\section{REFERENCES:}

1. Baradkar VP, Mathur M, Wanjari K and Kumar S. Candida in Pulmonary Tuberculosis. Bombay Hospital Journal, Special Issue, 2009; 52-53.

2. Kali A, Charles MP, Noyal MJ, Sivaraman U, Kumar S and Easow JM. Prevalence of Candida co-infection in patients with pulmonary tuberculosis. Australas Med J 2013; 6(8): 387-91.

3. Khanna BK, Nath P and Ansari AH. A study of mycotic flora of respiratory tract in pulmonary tuberculosis. Ind $\mathrm{J}$ Tuberc 1977; 24: 159-62.

4. Jain SK, Agrawal RL, Pandey RC, Agrawal M and Sharma S. A clinico-radiological study of secondary mycoses in pulmonary tuberculosis. Ind J Med Sci 1991; 45:81-84.

5. Latha R et al. Study on the shifting patterns of Non Candida albicans Candida in lower respiratory tract infections and evaluation of the CHROMagar in identification of the Candida species. J Microbiol Biotech Res 2011; 1(3): 113119.
6. Sehar Afshan Naz and Perween Tariq. A study of the trend in prevalence of opportunistic candidal co-infections among patients of pulmonary tuberculosis. Pak. J. Bot 2004; 4: 857 862.

7. Agarwal S, Manchanda V, Verma N and Bhalla P. Yeast identification in routine clinical microbiology laboratory and its clinical relevance. Indian Journal of Medical Microbiology 2011; 29(2): 172-177.

8. Longo LB, Harbuck AB and Fleischmann W. Coexistence of fungi and Tubercle Bacilli. Dis Chest 1958; 33:398-400.

9. Rathod VS, Raut JS and Mohan Karuppayil S. Antifungal Drug Susceptibility of Candida albicans isolates from pulmonary tuberculosis patients. Int J Pharm Pharm Sci 2012; Vol 4, Suppl 5: 323-326.

10. Phukan AC, Sarmabordoloi JN and Mahanta J. Bronchopulmonary Candidiasis in a tertiary referral hospital of Assam, India. Ind J Med Sci 2000; 54: 491-494. 